\title{
Duvernoy's Gland Transcriptomics of the Plains Black-Headed Snake, Tantilla nigriceps (Squamata, Colubridae): Unearthing the Venom of Small Rear-Fanged Snakes
}

\author{
Erich P. Hofmann ${ }^{1,+(\mathbb{D}, \text { Rhett M. Rautsaw }}{ }^{1} \mathbb{D}$, Andrew J. Mason ${ }^{1, \ddagger} \mathbb{D}$, Jason L. Strickland ${ }^{1, \S(\mathbb{D})}$ \\ and Christopher L. Parkinson ${ }^{1,2}, *$ (D)
}

1 Department of Biological Sciences, Clemson University, Clemson, SC 29634, USA; ephofmann564@cfcc.edu (E.P.H.); rrautsa@clemson.edu (R.M.R.); mason.501@osu.edu (A.J.M.); jasonstrickland@southalabama.edu (J.L.S.)

2 Department of Forestry and Environmental Conservation, Clemson University, Clemson, SC 29634, USA

* Correspondence: viper@clemson.edu

+ Current address: Science Department, Cape Fear Community College, Wilmington, NC 28401, USA.

$\ddagger$ Current address: Department of Evolution, Ecology and Organismal Biology, The Ohio State University, Columbus, $\mathrm{OH} 43210$, USA.

$\S$ Current address: Department of Biology, University of South Alabama, Mobile, AL 36688, USA.

check for updates

Citation: Hofmann, E.P.; Rautsaw, R.M.; Mason, A.J.; Strickland, J.L.; Parkinson C.L. Duvernoy's Gland Transcriptomics of the Plains Black-Headed Snake, Tantilla nigriceps (Squamata, Colubridae): Unearthing the Venom of Small Rear-Fanged Snakes. Toxins 2021, 13, 336. https:// doi.org/10.3390/toxins13050336

Received: 16 April 2021

Accepted: 4 May 2021

Published: 6 May 2021

Publisher's Note: MDPI stays neutra with regard to jurisdictional claims in published maps and institutional affiliations.

Copyright: (c) 2021 by the authors. Licensee MDPI, Basel, Switzerland. This article is an open access article distributed under the terms and conditions of the Creative Commons Attribution (CC BY) license (https:// creativecommons.org/licenses/by/ $4.0 /)$.

\begin{abstract}
The venoms of small rear-fanged snakes (RFS) remain largely unexplored, despite increased recognition of their importance in understanding venom evolution more broadly. Sequencing the transcriptome of venom-producing glands has greatly increased the ability of researchers to examine and characterize the toxin repertoire of small taxa with low venom yields. Here, we use RNA-seq to characterize the Duvernoy's gland transcriptome of the Plains Black-headed Snake, Tantilla nigriceps, a small, semi-fossorial colubrid that feeds on a variety of potentially dangerous arthropods including centipedes and spiders. We generated transcriptomes of six individuals from three localities in order to both characterize the toxin expression of this species for the first time, and to look for initial evidence of venom variation in the species. Three toxin families-three-finger neurotoxins (3FTxs), cysteine-rich secretory proteins (CRISPs), and snake venom metalloproteinases (SVMPIIIs) dominated the transcriptome of T. nigriceps; $3 F T x$ themselves were the dominant toxin family in most individuals, accounting for as much as $86.4 \%$ of an individual's toxin expression. Variation in toxin expression between individuals was also noted, with two specimens exhibiting higher relative expression of c-type lectins than any other sample $(8.7-11.9 \%$ compared to $<1 \%)$, and another expressed CRISPs higher than any other toxin. This study provides the first Duvernoy's gland transcriptomes of any species of Tantilla, and one of the few transcriptomic studies of RFS not predicated on a single individual. This initial characterization demonstrates the need for further study of toxin expression variation in this species, as well as the need for further exploration of small RFS venoms.
\end{abstract}

Keywords: colubrid; Duvernoy's gland secretion; rear-fanged snake; RNA-seq; transcriptomics; venom

Key Contribution: In the first transcriptomic investigation of Tantilla Duvernoy's glands, we determined that Tantilla nigriceps primarily expressed three-finger neurotoxins, cysteine-rich secretory proteins, and snake venom metalloproteinases; variation in the proportion of toxin expression among the six individuals sampled was also noted. Our work provides new insight into the venom composition of an often-overlooked clade of small, rear-fanged snakes.

\section{Introduction}

Venom has independently evolved over 100 times across the Tree of Life, amounting to more than 200,000 species which use this protein and peptide mixture for prey capture 
and predator defense [1-4]. Snakes have evolved several different venom delivery systems primarily for prey capture $[5,6]$. Solenoglyphous and proteroglyphous ("front-fanged") taxa-those with moveable or fixed hollow front fangs that deliver venom from a pressurized venom gland, such as vipers and elapids-have been focal systems in venom research, providing invaluable insight into ecology and natural history [7-11], evolution and phylogenetic patterns [12-15], behavior and physiology [16-18], and importantly the global snakebite epidemic $[19,20]$. Studies expanded to include distinct populations and range-wide sampling have further provided insight into intraspecific venom variation and gene evolution [13,21-24]. Not surprisingly, this focus on charismatic and medicallysignificant vipers and elapids has greatly outpaced the body of literature on the venoms of opisthoglyphous ("rear-fanged") colubrid snakes, the majority of which are not considered dangerous to humans $[25,26]$.

Many rear-fanged colubrid snakes (RFS) are capable of immobilizing and incapacitating prey by means of venom produced in a Duvernoy's gland (DVG) posterior to the eye [12,27-32]. Typically, these branched serous glands have neither an associated muscle insertion (for pressurization) nor the capacity for storage of large amounts of its toxic secretion [29,32]; instead, a duct system funnels these low-pressure venoms to solid, grooved rear fangs to then be delivered into captured prey $[29,32,33]$. RFS are increasingly being recognized as important pieces largely missing from the broader context of venom evolution, variation, and ecological significance [25,26,31,34-37]. When modern transcriptomic and/or proteomic methods have been applied, RFS have been shown to harbor tremendous toxin diversity, including novel phenotypes (e.g., [38]), prey-specific toxins (e.g., [39,40]), and novel components not previously considered venoms (e.g., [41]).

Historically, the small size of some RFS species and low venom yields from their DVG have limited the ability of researchers to characterize their venom phenotypes and genotypes, leading to the substantial gap in knowledge of venom composition between RFS and front-fanged taxa. Modern transcriptomic methods can overcome the limitations of small input size [42], and have been utilized to effectively characterize venoms from miniscule taxa, including a number of venomous invertebrates (e.g., [43-45]). Still, transcriptomic analyses of snake venom glands have been almost entirely limited to larger-bodied species and/or those whose venom is considered medically-significant to humans ([46] and references therein). To this point, a recent summary of snake venom gland transcriptomes by Modahl et al. [46] noted that RFS account for only $23 \%$ of species with published transcriptomes (15 of 65), despite accounting for approximately two-thirds of snake biodiversity [47,48]; almost all of these RFS with sequenced glands are larger bodied taxa. Thus, a substantial percentage of venom-producing snakes have not been studied with modern methods, but are crucial to our understanding of venom evolution, function, and diversity in need of further exploration.

Snakes in the genus Tantilla are one such clade of RFS that are known to produce venom, but the composition of their venom remains almost completely unknown [27,49-53]. The genus includes 67 species of small-bodied (most $<25 \mathrm{~cm}$ total length), semi-fossorial, opisthoglyphous colubrids distributed across North and Central America $[48,54,55]$. Although natural history data is lacking for many species due to their cryptic nature, Tantilla are broadly considered to primarily consume arthropods, including potentially dangerous prey items such as centipedes, scorpions, and spiders [51,56-58]. Tantilla possess a DVG, grooved and enlarged rear fangs, and a low-pressure venom yield, allowing them to subdue prey items as quickly as or faster than venomous front-fanged species take down prey $[28,29,56,59,60]$. Their small size, reluctance to bite, and very low venom yield precludes these snakes from posing any threat to humans, and makes them challenging to study $[49,52]$.

Tantilla venom has largely gone unstudied; only two species-T. nigriceps and T. cucullata - have been investigated in any detail as part of broader proteomic studies $[40,52,53]$. Tantilla nigriceps is widely distributed in the Chihuahuan Desert and Great Plains of the central United States and northern Mexico [56,61] and are known to predate potentially 
dangerous prey items including spiders, centipedes, scorpions, millipedes, and various insects [57,62]. Using enzymatic assays, Hill and Mackessy [53] detected low levels of snake venom metalloproteinase (SVMP) activity in two samples of T. nigriceps venom as part of a larger study across North American colubrids (see also Saviola et al. [63]). Additionally, Hill and Mackessy [53] recovered a fragment of a peptide hypothesized to be a novel vascular endothelial growth factor toxin (VEGF). An SDS-PAGE profile including a T. cucullata venom sample was published as a supplemental figure in Modahl et al. [40], providing evidence of SVMPIIIs and CRISPs in the venom of that species. Beyond these initial works, no further attempts to fully characterize any Tantilla venom have been published, and more generally, no DVG transcriptomes have been sequenced from any species of this genus.

Given this void in our understanding of small RFS venoms, we chose to characterize the Duvernoy's gland transcriptome of the Plains Black-headed Snake, Tantilla nigriceps, to provide new insight into the toxin composition of these snakes. To this end we utilized mRNA sequencing to characterize the DVG transcriptomes from six individuals across three localities, and tested for differences in expression across these locations. Based on the only previous study of T. nigriceps venom, we predicted SVMP transcripts would dominate toxin expression in DVG transcriptomes, with additional toxin families such as cysteine-rich secretory proteins (CRISPs) being present, but more lowly expressed. We also predicted we would find subtle intraspecific variation in venom expression between samples from different localities, but not significant differential expression between samples, as the natural history of the species (as currently understood) is similar across the areas sampled.

\section{Results}

We sequenced the DVG transcriptomes of six adult Tantilla nigriceps collected in Texas and New Mexico (Table 1; Figure 1) using 150 base-pair (bp) paired-end transcriptome sequencing on the Illumina NovaSeq and NextSeq platforms. Summary statistics for the six DVG transcriptomes are in Table 1. For each individual, we generated 8,088,121$28,872,668$ read pairs (average: $20,075,935 \pm 7,332,393$ ) of which $73.7-83.4 \%$ were merged (average: $79.6 \pm 3.1 \%$ ). Following assembly, annotation, duplicate and chimera removal, and clustering, we combined the annotated transcripts from each assembly into a consensus transcriptome. This consensus transcriptome consisted of 36 unique putative toxin transcripts-primarily comprising four toxin families-and 2409 unique nontoxin transcripts (Table 2; Figure 2). The unique toxins accounted for $63.7 \%$ of the consensus expression based on RSEM-mapped reads across the six individuals (Supplementary Data 1).

Table 1. Metadata and sequencing outputs of Tantilla nigriceps used in this study.

\begin{tabular}{ccccrr}
\hline ASNHC No. & Field ID & Locality & Sex & Read Pairs & Merged Reads \\
\hline 15178 & CLP2590 & Hudspeth Co., TX, USA & F & $27,832,797$ & $22,093,170$ \\
15179 & CLP2591 & Hudspeth Co., TX, USA & M & $28,872,668$ & $24,078,211$ \\
15180 & CLP2592 & Duval Co., TX, USA & F & $22,736,233$ & $17,826,005$ \\
15181 & CLP2753 & Hidalgo Co., NM, USA & F & $14,445,533$ & $10,648,351$ \\
15182 & CLP2754 & Hidalgo Co., NM, USA & M & $8,088,121$ & $6,232,048$ \\
15183 & CLP2759 & Hidalgo Co., NM, USA & M & $18,480,258$ & $15,030,748$ \\
\hline
\end{tabular}




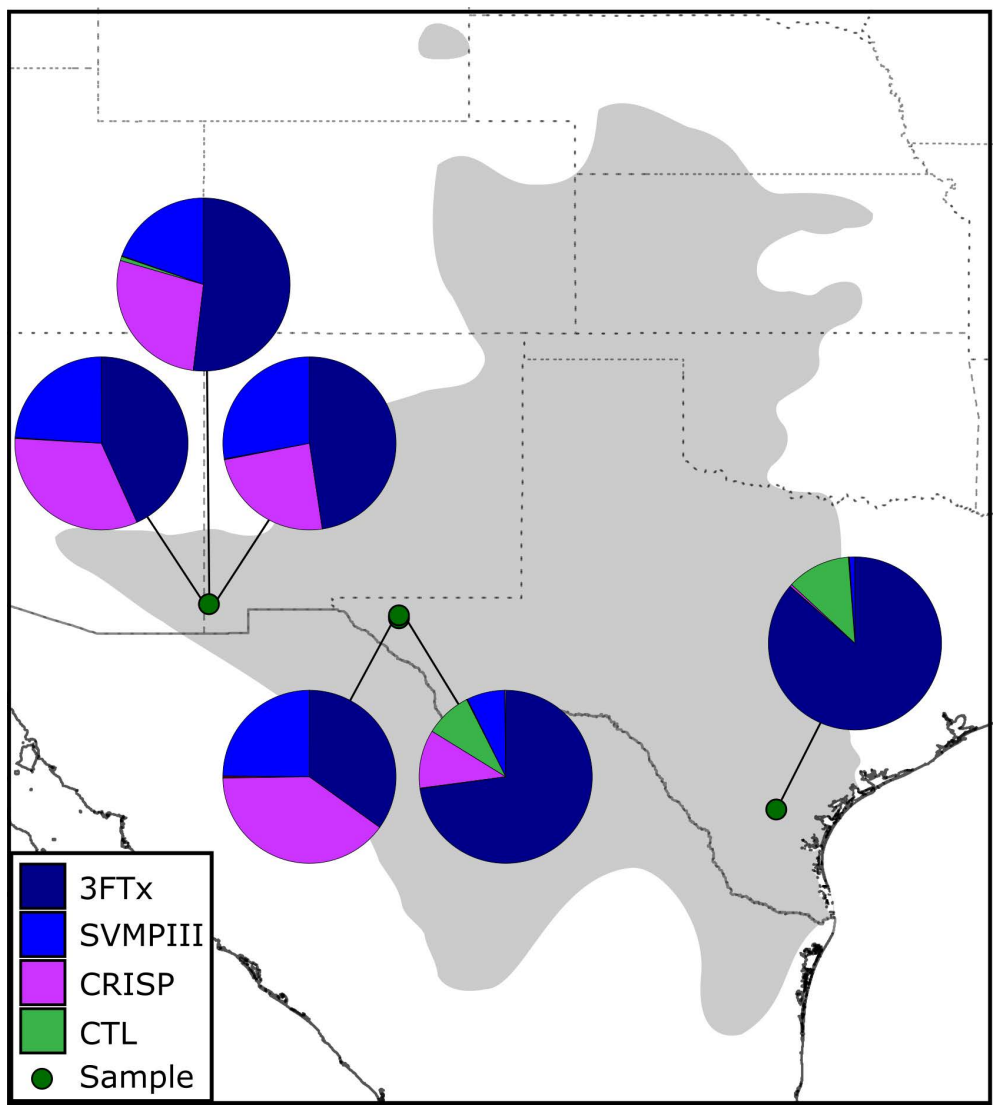

Figure 1. Sampling localities and associated DVG transcriptome of Tantilla nigriceps used in this study. The shaded gray area on the map represents the approximate range of $T$. nigriceps modified from Ernst and Ernst [56]. Pie charts indicate the proportional contribution of each of the four major toxin families recovered to the overall toxin transcriptome.

Table 2. Percent contribution of the most highly expressed toxin families to the overall toxin transcriptome. Percentages calculated by summing individual toxin transcripts by family and dividing by the total toxin TPM. Values rounded to the nearest $0.1 \%$.

\begin{tabular}{cccccccc}
\hline & ASNHC & ASNHC & ASNHC & ASNHC & ASNHC & ASNHC & Avg. \\
& $\mathbf{1 5 1 7 8}$ & $\mathbf{1 5 1 7 9}$ & $\mathbf{1 5 1 8 0}$ & $\mathbf{1 5 1 8 1}$ & $\mathbf{1 5 1 8 2}$ & $\mathbf{1 5 1 8 3}$ & \\
\hline 3FTx & $34.9 \%$ & $72.8 \%$ & $86.4 \%$ & $51.9 \%$ & $47.6 \%$ & $43.3 \%$ & $54.3 \%$ \\
CRISP & $39.8 \%$ & $10.9 \%$ & $0.4 \%$ & $27.6 \%$ & $24.3 \%$ & $32.7 \%$ & $24.0 \%$ \\
SVMPIII & $24.8 \%$ & $7.1 \%$ & $1.0 \%$ & $19.6 \%$ & $27.9 \%$ & $23.9 \%$ & $18.4 \%$ \\
CTL & $<0.1 \%$ & $8.7 \%$ & $11.9 \%$ & $0.8 \%$ & $<0.1 \%$ & $<0.1 \%$ & $3.1 \%$ \\
Others & $0.4 \%$ & $0.43 \%$ & $0.3 \%$ & $0.1 \%$ & $0.2 \%$ & $0.1 \%$ & $0.2 \%$ \\
\hline
\end{tabular}

The Tantilla nigriceps DVG transcriptome is dominated by three toxin families: threefinger toxins (3FTxs), cysteine-rich secretory proteins (CRISPs), and snake venom metalloproteinases (SVMPIIIs) (Table 2). Two individuals exhibited relatively high expression of c-type lectins (CTLs), as well. 3FTxs were especially abundant, with nine unique transcripts accounting for more than $33 \%$ of the average total transcriptome expression and more than $54 \%$ of average toxin expression. Two unique CRISP transcripts accounted for a combined $14.6 \%$ of average total transcriptome expression and $24.0 \%$ of toxin expression, whereas the eight unique SVMPIIIs collectively accounted for $11.2 \%$ of total transcriptome expression and $17.5 \%$ of toxin expression. The seven unique CTLs recovered accounted for $1.9 \%$ of total transcriptome expression and $3.1 \%$ of toxin expression. Eight additional toxin families-some of which may have no function or only indirect toxin function [65] —were recovered in much lower abundance ( $<1 \%$ of both total and toxin expression): three acetyl- 
cholinesterases (AChEs), one fused toxin, one Kunitz-type proteinase inhibitor (KUN), one phosphodiesterase (PDE4), one phospholipase-A2 (PLA2), one phosopholipase-B (PLB), one vascular endothelial growth factor (VEGF), and one waprin.

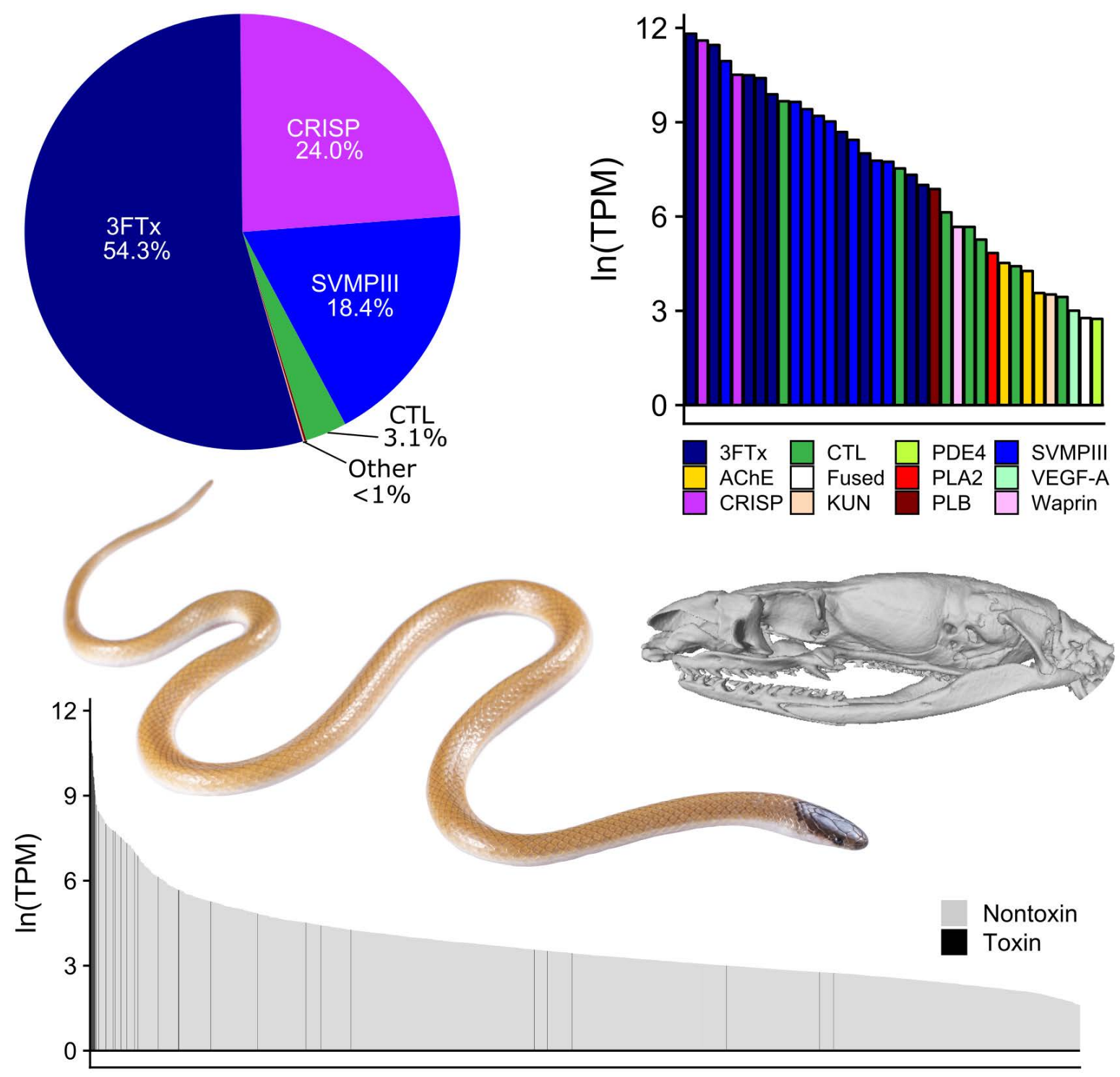

Figure 2. Expression of the Duvernoy's gland transcriptome of Tantilla nigriceps. Data is the average of six individuals (see Figure S1 for individual data). The pie chart represents proportional toxin gene expression by toxin family. The colored barchart represents expression of each toxin transcript, and the bottom black-and-white graph represents toxin and nontoxin gene expression in the Duvernoy's gland. Photo of T. nigriceps in life by T. Schramer. Inset skull scan of UMMZ:Herps:69019 accessed via MorphoSource (ark:/87602/m4/M39216) [64]; skull not to scale of inset photo.

Broadly, the five individuals collected in the Chihuahuan Desert expressed similar toxin transcriptomes dominated by the aforementioned 3FTxs (34.9-72.8\% of toxin expression), CRISPs (11.0-39.8\%), and SVMPIIIs (7.1-27.9\%). Conversely, the one individual collected in the Great Plains-ASNHC 15180-expressed the highest proportion of 3FTxs $(86.4 \%)$, as well as a substantially higher proportion of CTLs (11\% of toxin expression), with less than $1 \%$ of the toxin expression dedicated to CRISPs or SVMPIIIs (Figure 1; Table 2; Figure S1). CTLs accounted for more than $1 \%$ of the total toxin expression in only one individual from the Chihuahuan Desert (ASNHC 15179: 8.7\%). 
We tested for significant differences in toxin expression across life history traits using DESeq2 [66] and edgeR [67] as a preliminary look into intraspecific venom variation. No significant differences between sex or state of origin, or across SVL, were detected concordantly by both analyses (Table S1). Testing latitude as a continuous variable, 13 toxin transcripts (six 3FTxs, both CRISPs, and five SVMPIIIs) and two toxin families (CRISPs and SVMPIIIs) were considered significantly differentially expressed; across longitude, two transcripts (a 3FTx and the VEGF) and one family (VEGF) were significantly differentially expressed (Table S1). Clearly, more complete sampling across the distribution of the species is needed to determine if any of these significant differences (or the lack thereof) are indicative of broader patterns of venom variation in T. nigriceps, or artifacts of sampling bias.

\section{Discussion}

Our study provided the first look into the DVG transcriptome of any species of Tantilla, and a major step towards the characterization of T. nigriceps venom. In contrast to our predictions, T. nigriceps venom expression was not dominated by SVMPs, but instead by short neurotoxic 3FTxs in most individuals. Indeed, nine 3FTx transcripts accounted for more than half of the average toxin expression of T. nigriceps (Table 2) and more than a third of the overall expression in the DVG. CRISPs and SVMPIIIs were also highly expressed, but not to the level of 3FTxs in most individuals.

RFS are generally characterized as having either an elapid-like neurotoxic venom (dominated by 3FTxs), or an enzymatic, viper-like venom (dominated by SVMPs) [26,68]. For example, sixteen unique 3FTxs together make up $60 \%$ of the elapid-like transcriptome of Spilotes sulfureus; an SVMP is present, but accounts for only $2 \%$ of the total toxin expression. Conversely, SVMPs dominate the transcriptomes of Ahaetulla prasina (62\%) and Borikenophis portoricensis (70\%; [69], as well as Hypsiglena sp. (68\%; [68]); 3FTxs, while present, are more lowly expressed $(17 \%, 1 \%$, and $<1 \%$ respectively). As 3FTxs were the dominant toxin family recovered in the consensus transcriptome-as well as in five of the six individuals sequenced-our results suggest that the venom of Tantilla nigriceps is most similar to the elapid-like, 3FTx-dominant category. However, the venom does not necessarily fall cleanly into this category given the individual variation recovered. 3FTxs accounted for 34.9-86.4\% of the individual toxin transcriptomes (Table 2). CRISPs and SVMPIIIs were highly variable in expression, and in one individual CRISPs were the most highly expressed toxin family. This diversity of highly expressed SVMPIIIs, 3FTxs, and CRISPs is reminiscent of Boiga irregularis, whose transcriptome is dominated by these same three toxin families, each with transcripts contributing substantially to the overall transcriptome [68].

Capturing variation in venom expression in T. nigriceps was only possible by having multiple samples from different localities. Few studies have generated RFS transcriptomes from more than a single individual, thus precluding any look at intraspecific variation in expression. Differences in toxin expression were evident between our samples from different localities (Figure 1). The lone sample from Duval County, Texas, for example, largely lacked SVMPs and CRISPs, instead expressing CTLs as its second-most dominant toxin family (Table 2) and expressing 3FTxs as a higher proportion of its transcriptome than any other sample. Moderate expression of SVMPs in other samples-especially in those from the Chihuahuan Desert-demonstrate the necessity of more complete transcriptomic sampling across its range. Transcriptomes from populations to the north (e.g., Colorado, Nebraska, and Kansas) and south (Mexico) would paint a clearer picture of venom expression variation as it relates to biogeographical (and potentially ecological) differences. Expression differences across individuals and habitats could be local adaptations in response to environmental or ecological selective pressures, or simply intraspecific variation that is difficult to explore with limited sample sizes. Though the difficulty of venom extraction and low yields from small RFS hinders proteomic characterization of T. nigriceps venom, these methods (undertaken by patient researchers) are critical to uncovering the functional activity of venom of these snakes. 
By sequencing multiple individuals, we also hoped to recover an exact transcript match to the $3.5 \mathrm{kD}$ peptide fragment discovered by Hill and Mackessy [53]. They hypothesized it to be a novel VEGF toxin based on the alignment of six of the 14 residues to a human VEGF sequence but were unable to otherwise identify it conclusively. We were unable to find an exact match to the fragment in our consensus transcriptome, but did align the same six residues with a VEGF transcript recovered in our transcriptome. This VEGF was lowly expressed $(<0.0001 \%$ of average toxin TPM) and may not be a major component of the venom phenotype. Interestingly, we were able to align seven residues with transcript 3FTx-5 and six with 3FTx-1 - the fifth- and first-most highly expressed 3FTxs based on average TPM. As 3FTxs were highly expressed in all individuals (and thus likely a major component of the venom phenotype), Hill and Mackessy [53]'s fragment might instead be a portion of a short neurotoxin. Characterization of transcriptomes from additional localities might clarify the identity of this toxin fragment and its role in the venom of T. nigriceps.

It is clear that further exploration of Tantilla nigriceps venom-and the venom of other species of Tantilla-is warranted. Variation in the venom transcriptome and venom proteome across the genus is likely given their phylogenetic and ecological diversity. To this point, Modahl et al. [40]'s SDS-PAGE profile for T. cucullata did not provide any evidence of 3FTxs, the most abundant toxin family in the transcriptome of T. nigriceps. While Tantilla are broadly considered to predate predominantly centipedes [58,70], some species are known to consume primarily beetle larvae [71] or a wider variety of arthropod prey including spiders, scorpions, and potentially even other small snakes [62]. Differences in the danger posed by certain prey items (e.g., centipedes) relative to others (e.g., beetle larvae) might correlate to compositional and/or functional variation of the venoms of different taxa, or different populations of the same taxon.

Small rear-fanged snake species represent an informative but neglected component in our understanding of venom evolution. Although this gap in knowledge has been pointed out numerous times (e.g., $[25,26,31,34,37])$, the vast majority of small RFS venoms still have not been afforded even cursory investigations. This dichotomy between recognized importance and continued neglect is underscored by the fact that, when studied, colubrid venoms are a source of incredible toxin diversity and even novel toxins (and toxin families). Transcriptomic and proteomic studies of colubrid venoms have also unlocked important new insights into the ecology, evolution, and natural history of the snakes themselves (e.g., [38-40,69]). Without an understanding of these key, overlooked components, the broader picture of venom evolution as a whole will remain incomplete.

\section{Conclusions}

In this study, we present the first Duvernoy's gland transcriptomes of six Tantilla nigriceps from three localities in the southern United States. Three-finger toxins, cysteine-rich secretory proteins, and snake venom metalloproteinases were the most highly expressed toxin families, and two snakes also exhibited moderate expression of c-type lectins. Our results provide the first transcriptomic characterization of the Duvernoy's gland of any Tantilla species, and highlight the need for further investigation into the venom of these and other small, semi-fossorial rear-fanged snakes.

\section{Materials and Methods}

\subsection{Sample and Gland Collection}

Six adult Tantilla nigriceps were opportunistically collected from Texas in June 2017 and New Mexico in August 2018 (Figure 1; Table 1). Five individuals were collected from the Chihuahuan Desert and one was collected from the Great Plains. We collected venom following a modified protocol similar to Rosenberg [33] and Hill and Mackessy [52]. Briefly, snakes were anesthetized using isoflurane until fully relaxed, and a $6 \mu \mathrm{g} / \mathrm{g}$ dose of pilocarpine was subcutaneously injected into the dorsolateral aspect of the snake, approximately $2 \mathrm{~cm}$ posterior to the head. Saliva from the oral cavity was collected using a micropipette, and venom was collected by using thin capillary tubes and/or 2-20 $\mu \mathrm{L}$ micropipette tips placed 
over the enlarged rear fangs. Due to the small size of the snakes-none weighed more than $2.5 \mathrm{~g}$ - very low venom yields were recovered. Four days after venom extraction, snakes were euthanized using a two-step MS-222 injection [72]. Both the left and right DVG of each individual were excised and immediately placed in RNAlater, briefly stored at $4{ }^{\circ} \mathrm{C}$, and then transferred to long-term storage at $-80^{\circ} \mathrm{C}$. Snakes were collected and research carried out under the following permits and protocols: New Mexico Department of Game and Fish Scientific Collecting Permit (NM SCP\# 3697), Texas Parks and Wildlife Scientific Permit for Research (TX SCP\# SPR-0390-029). Specimens were deposited in the Angelo State Natural History Collections (ASNHC). A CT scan of a T. nigriceps (UMMZ:Herps:69019) skull was retrieved from MorphoSource (ark:/87602/m4/M39216) [64].

\subsection{RNA Extraction and Sequencing}

We isolated RNA from the excised Duvernoy's glands by means of a standard TRIzol extraction, as described by [73-75]. Briefly, DVG were finely minced, placed in TRIzol solution (Invitrogen), then homogenized and transferred to phase lock heavy gel tubes (5Prime). Total RNA was subsequently isolated using chloroform, then purified using isopropyl alcohol and ethanol precipitation. RNA was quantified using either a Qubit RNA BroadRange or High Sensitivity Kit, depending on the whether a quantifiable amount was detected on a first attempt. We used a Bioanalyzer 2100 and RNA 6000 Pico Kit (Agilent Technologies) to determine RNA quality and to ensure there was sufficient RNA to continue with cDNA library preparation and sequencing. From the isolated mRNA, we produced cDNA libraries using magnetic bead isolation of mRNA, and subsequent cDNA synthesis and PCR amplification. We used the NEBNext Poly(A) mRNA Magnetic Isolation Module (NEDB \#E7490S) with equal input amounts of extracted RNA from the left and right glands of each individual to isolate mRNA. Following bead isolation and cleanup, we prepared cDNA libraries using a NEB Next Ultra RNA Library Prep Kit for Illumina (NEB \#E7530). To achieve a target mean fragment size of $400 \mathrm{bp}$, we used a fragmentation time of $13 \mathrm{~min}, 30 \mathrm{~s}$. For amplification of double-stranded cDNA libraries, we used 14 PCR cycles. We used a Qubit dsDNA High Sensitivity Kit and a Bioanalyzer 2100 with a DNA High Sensitivity Kit to determine library yield and quality. We determined the total concentration of amplifiable cDNA in each library using a KAPA qPCR (Roche KK4873). We performed a final concentration and quality check on the pooled libraries on the Bioanalyzer 2100 and via a KAPA qPCR. Pooled libraries were sequenced with 150 bp paired-end reads on either an Illumina NovaSeq 6000 platform at Florida State University College of Medicine Translational Science Laboratory (ASNHC 15178-15182) or an Illumina NextSeq 550 platform at the Clemson University Genomics and Bioinformatics Facility (ASNHC 15183).

\subsection{Transcriptome Assembly and Annotation}

We trimmed reads of base calls $<5$ using Trim Galore! v. 0.4.4 (https://github. com/FelixKrueger/TrimGalore, accessed on 6 May 2019) and merged them using PEAR v. 0.9.10 [76]. We then performed de novo assembly using three different assembly methods, following the recommendations of Holding et al. [77]: Extender [73], SeqMan NGen v. 14 (using the Lasergene DNAStar software package; Madison, WI, USA: https: / / www.dnastar. com/t-nextgen-seqman-ngen.aspx, accessed on 6 May 2019), and Trinity v. 2.0.3 [78]. This combination of assemblers best captures the full repertoire of toxin and nontoxin genes from venom gland transcriptomes [77].

We annotated the assembled contigs from each assembler via blastx searches against the UniProt animal venom proteins and toxins database (http://www.uniprot.org/ program/Toxins, accessed on 6 May 2019), using a minimum e-value of $10^{-4}$. We annotated both toxins and nontoxins by using cd-hit-est [79] to cluster sequences to a custom database of previously-annotated snake toxins and nontoxins; sequences and their associated signal peptides were automatically annotated when match percentages were $>80 \%$. We then manually annotated the remaining toxin and nontoxin contigs by comparing 
sequences to blastx results, as in [22]. Once annotation was complete, we combined annotated transcripts from the three assemblers and removed duplicates. We then screened for chimeric sequences by using BWA-MEM [80] to align merged reads to the annotated transcripts, removing reads with mismatches such as gaps or nucleotide differences. Any transcript with no coverage at any base was removed automatically. Additional transcripts were manually checked if the difference in the average length of reads on either side of a given site was greater than $75 \%$. We then clustered the remaining transcripts of each individual using cd-hit-est at a threshold of $98 \%$ in order to reduce the redundancy of single locus allelic variation. Finally, we produced a species consensus transcriptome by combining the de novo-assembled transcriptomes of all six individuals and clustering them using cd-hit-est at a threshold of 95\%. Transcripts were translated into amino acid sequences using the Sequence Manipulation Suite [81].

\subsection{Transcriptomic Analyses}

Using RSEM [82] with the default Bowtie 2 alignment settings [83], we mapped merged reads from each individual to the consensus transcriptome to determine expected counts (EC) of reads mapping to transcripts and calculate the normalized metric of transcripts per million reads (TPM). Zero-values were imputed using the 'cmultRepl' function in the zCompositions $\mathrm{R}$ package [84]. In addition to these metrics for each toxin transcript, we summed TPM and EC across paralogous toxins from the same gene family to visualize and analyze variation across toxin families. We visualized toxin composition of individuals and the consensus using TPM.

To investigate venom variation in Tantilla nigriceps, we used DESeq2 [66] and edgeR [67] to test for differential expression across life history traits. We tested for differences across body size (SVL), sex, and location. Five of our samples were collected from the Chihuahuan Desert, while a single individual was from the Great Plains in southern Texas. Without biological replicates, we did not have the statistical power to test for differential expression between individuals in the different biomes, so we instead used latitude and longitude as continuous variables in order to see if, preliminarily, there were differences that may be ascribed to those areas worth further investigation in the future. Expected counts for each venom transcript and summed expected counts for toxin families were used for these analyses. For DESeq2 analyses, we performed Wald significance tests with a local fit of dispersions and corrected $p$-values for false-discovery rate (FDR). For edgeR analyses, we fit negative binomial generalized linear models for each gene and tested for significance with likelihood ratio tests; $p$-values were corrected for FDR as in DESeq2 analyses. We considered genes or gene families significantly differentially expressed if they were found to have FDR-corrected $\alpha<0.05$ by both analyses.

Supplementary Materials: The following are available online at https:/ / www.mdpi.com/article/ 10.3390/toxins13050336/s1: Supplementary Data 1: Metadata and RSEM results (TPM and EC). Data includes transcripts per million (TPM) and expected counts (EC) of individual transcripts and combined families, arranged by individual specimen, averaged by localities, and averaged across all specimens. Table S1: DESeq2 and edgeR results. Figure S1: Expression of the Duvernoy's gland transcriptomes of individual Tantilla nigriceps.

Author Contributions: Conceptualization: E.P.H. and C.L.P.; investigation, methodology, and formal analyses: E.P.H., R.M.R., A.J.M. and J.L.S.; writing—original draft: E.P.H.; writing-review and editing: R.M.R., A.J.M., J.L.S. and C.L.P.; data curation: R.M.R. and C.L.P.; resources and funding acquisition: C.L.P. All authors have read and agreed to the published version of the manuscript.

Funding: This work was funded by NSF Grants DEB 1638879, \& 1822417 to CLP, plus startup funds from Clemson University to CLP.

Institutional Review Board Statement: All animal work was approved by the Clemson University Institute for Animal Care and Use Committee \#2017-067.

Informed Consent Statement: Not applicable. 
Data Availability Statement: The data underlying this article are available in its online supplementary material and the National Center for Biotechnology Information (NCBI). RNA sequencing data were submitted to the Sequence Read Archive (SRA) under BioProject (PRJNA88989). BioSamples accession numbers (SAMN18863717-SAMN18863722). SRR accession numbers (SRR14319402SRR14319407).

Acknowledgments: Sampling in Texas was undertaken by T. Petty, and M. Holding facilitated sampling in New Mexico and generated some of the sequence data used herein; we greatly appreciate the efforts of both. T. Schramer provided photos of a T. nigriceps collected by S. Ellsworth and G. Nystrom. We thank M. Dixon and D. Krejsa for accessioning the specimens at ASNHC. Clemson University generously provided computational resources on their Palmetto Cluster. For providing the dataset and facilitating the use of the CT-scan of UMMZ:Herps:69019 (ark:/87602/m4/M39216) we thank A. Davis Rabosky, R. Nagesan, the "Scan All Snakes" (NSF DBI-1701714), "oVertTCN" Projects (NSF DBI-1701713), and the University of Michigan Museum of Zoology, as well as MorphoSource for hosting the data. Finally, we thank two anonymous reviewers for their comments and suggestions.

Conflicts of Interest: The authors declare no conflict of interest.

\section{References}

1. Casewell, N.R.; Wüster, W.; Vonk, F.J.; Harrison, R.A.; Fry, B.G. Complex cocktails: The evolutionary novelty of venoms. Trends Ecol. Evol. 2013, 28, 219-229. [CrossRef] [PubMed]

2. Schendel, V.; Rash, L.D.; Jenner, R.A.; Undheim, E.A. The diversity of venom: The importance of behavior and venom system morphology in understanding its ecology and evolution. Toxins 2019, 11, 666. [CrossRef] [PubMed]

3. Zancolli, G.; Casewell, N.R. Venom systems as models for studying the origin and regulation of evolutionary novelties. Mol. Biol. Evol. 2020, 37, 2777-2790. [CrossRef] [PubMed]

4. Kazandjian, T.D.; Petras, D.; Robinson, S.D.; Van Thiel, J.; Greene, H.W.; Arbuckle, K.; Barlow, A.; Carter, D.A.; Wouters, R.M.; Whiteley, G.; et al. Convergent evolution of pain-inducing defensive venom components in spitting cobras. Science 2021, 371, 386-390. [CrossRef]

5. Deufel, A.; Cundall, D. Functional plasticity of the venom delivery system in snakes with a focus on the poststrike prey release behavior. Zool. Anz. 2006, 245, 249-267. [CrossRef]

6. Ward-Smith, H.; Arbuckle, K.; Naude, A.; Wüster, W. Fangs for the memories? A survey of pain in snakebite patients does not support a strong role for defense in the evolution of snake venom composition. Toxins 2020, 12, 201. [CrossRef]

7. Holding, M.L.; Biardi, J.E.; Gibbs, H.L. Coevolution of venom function and venom resistance in a rattlesnake predator and its squirrel prey. Proc. R. Soc. B. Biol. Sci. 2016, 283. [CrossRef]

8. Holding, M.L.; Margres, M.J.; Rokyta, D.R.; Gibbs, H.L. Local prey community composition and genetic distance predict venom divergence among populations of the Northern Pacific Rattlesnake (Crotalus oreganus). J. Evol. Biol. 2018, 31, 1513-1528. [CrossRef]

9. Davies, E.L.; Arbuckle, K. Coevolution of snake venom toxic activities and diet: Evidence that ecological generalism favours toxicological diversity. Toxins 2019, 11, 711. [CrossRef]

10. Healy, K.; Carbone, C.; Jackson, A.L. Snake venom potency and yield are associated with prey-evolution, predator metabolism and habitat structure. Ecol. Lett. 2019, 22, 527-537. [CrossRef]

11. Lyons, K.; Dugon, M.M.; Healy, K. Diet breadth mediates the prey specificity of venom potency in snakes. Toxins 2020, $12,74$. [CrossRef]

12. Savitzky, A.H. The role of venom delivery strategies in snake evolution. Evolution 1980, 34, 1194. [CrossRef]

13. Mason, A.; Margres, M.; Strickland, J.; Rokyta, D.; Sasa, M.; Parkinson, C. Trait differentiation and modular toxin expression in palm-pitvipers. BMC Genom. 2020, 21. [CrossRef]

14. Barua, A.; Mikheyev, A.S.; Russo, C. Many options, few solutions: Over 60 My snakes converged on a few optimal venom formulations. Mol. Biol. Evol. 2019, 36, 1964-1974. [CrossRef]

15. Barua, A.; Mikheyev, A.S. Toxin expression in snake venom evolves rapidly with constant shifts in evolutionary rates. Proc. $R$. Soc. Biol. Sci. 2020, 287. [CrossRef]

16. Young, B.A.; Lee, C.E.; Daley, K.M. Do snakes meter venom? BioScience 2002, 51, 1121-1126. [CrossRef]

17. Saviola, A.J.; Chiszar, D.; Busch, C.; Mackessy, S.P. Molecular basis for prey relocation in viperid snakes. BMC Biol. $2013,11$. [CrossRef]

18. Casewell, N.R.; Jackson, T.N.; Laustsen, A.H.; Sunagar, K. Causes and consequences of snake venom variation. Trends Pharmacol. Sci. 2020, 41, 570-581. [CrossRef]

19. Kasturiratne, A.; Wickremasinghe, A.R.; De Silva, N.; Kithsiri Gunawardena, N.; Pathmeswaran, A.; Premaratna, R.; Savioli, L.; Lalloo, D.G.; Janaka De Silva, H.; Winkel, K. The global burden of snakebite: A literature analysis and modelling based on regional estimates of envenoming and deaths. PLoS Med. 2008, 5. [CrossRef]

20. Gutiérrez, J.M.; Calvete, J.J.; Habib, A.G.; Harrison, R.A.; Williams, D.J.; Warrell, D.A. Snakebite envenoming. Nat. Rev. Dis. Prim. 2017, 3, 1-21. [CrossRef] 
21. Margres, M.J.; Wray, K.P.; Hassinger, A.T.; Ward, M.J.; McGivern, J.J.; Lemmon, E.M.; Lemmon, A.R.; Rokyta, D.R. Quantity, not quality: Rapid adaptation in a polygenic trait proceeded exclusively through expression differentiation. Mol. Biol. Evol. 2017, 34, 3099-3110. [CrossRef] [PubMed]

22. Hofmann, E.P.; Rautsaw, R.M.; Strickland, J.L.; Holding, M.L.; Hogan, M.P.; Mason, A.J.; Rokyta, D.R.; Parkinson, C.L. Comparative venom-gland transcriptomics and venom proteomics of four Sidewinder Rattlesnake (Crotalus cerastes) lineages reveal little differential expression despite individual variation. Sci. Rep. 2018, 8. [CrossRef] [PubMed]

23. Strickland, J.L.; Smith, C.F.; Mason, A.J.; Schield, D.R.; Borja, M.; Castañeda-Gaytán, G.; Spencer, C.L.; Smith, L.L.; Trápaga, A.; Bouzid, N.M.; et al. Evidence for divergent patterns of local selection driving venom variation in Mojave Rattlesnakes (Crotalus scutulatus). Sci. Rep. 2018, 8. [CrossRef] [PubMed]

24. Rautsaw, R.M.; Hofmann, E.P.; Margres, M.J.; Holding, M.L.; Strickland, J.L.; Mason, A.J.; Rokyta, D.R.; Parkinson, C.L. Intraspecific sequence and gene expression variation contribute little to venom diversity in Sidewinder Rattlesnakes (Crotalus cerastes). Proc. R. Soc. B. Biol. Sci. 2019, 286. [CrossRef]

25. Junqueira de Azevedo, I.L.M.; Campos, P.F.; Ching, A.T.C.; Mackessy, S.P. Colubrid venom vomposition: An -Omics perspective. Toxins 2016, 8, 230. [CrossRef]

26. Modahl, C.M.; Mackessy, S.P. Venoms of rear-fanged snakes: New proteins and novel activities. Front. Ecol. Evol. 2019, 7. [CrossRef]

27. McKinstry, D.M. Evidence of toxic saliva in some colubrid snakes of the United States. Toxicon 1978, 16, 523-534. [CrossRef]

28. Rodríguez-Robles, J.A. Are the Duvernoy's gland secretions of colubrid snakes venoms? J. Herpetol. 1994, 28, 388-390. [CrossRef]

29. Rodríguez-Robles, J.A.; Thomas, R. Venom function in the Puerto Rican Racer, Alsophis portoricensis (Serpentes: Colubridae). Copeia 1992, 1, 62-68. [CrossRef]

30. Kardong, K. Colubrid snakes and Duvernoy's “venom” glands. J. Toxicol. Rev. 2002, 21, 1-19. [CrossRef]

31. Mackessy, S.P.; Saviola, A.J. Understanding biological roles of venoms among the Caenophidia: The importance of rear-fanged snakes. Integr. Comp. Biol. 2016, 56, 1004-1021. [CrossRef]

32. Weinstein, S.; Smith, T.; Kardong, K. Reptile Venom Glands: Form, Function, and Future. In Handbook of Reptile Venoms and Toxins; Mackessy, S., Ed.; CRC, Taylor Francis: Boca Raton, FL, USA, 2010; pp. 65-91.

33. Rosenberg, H.I. An improved method for collecting secretion from Duvernoy's gland of colubrid snakes. Copeia 1992, 1992, 244246. [CrossRef]

34. Mackessy, S.P. Biochemistry and pharmacology of colubrid snake venoms. J. Toxicol. Toxin Rev. 2002, 21, 43-83. [CrossRef]

35. Fry, B.G.; Wüster, W.; Fadil, S.; Ramjan, R.; Jackson, T.; Martelli, P.; Kini, R.M. Analysis of Colubroidea snake venoms by liquid chromatography with mass spectrometry: Evolutionary and toxinological implications. Rapid Commun. Mass Spectrom. 2003, 17, 2047-2062. [CrossRef]

36. Modahl, C.M.; Saviola, A.J.; Mackessy, S.P. Venoms of Colubrids. In Venom Genomics and Proteomics; Gopalakrishnakone, P., Calvete, J., Eds.; Springer: Berlin, Germany, 2016; pp. 51-79. [CrossRef]

37. Jackson, T.N.W.; Jouanne, H.; Vidal, N. Snake venom in context: Neglected clades and concepts. Front. Ecol. Evol. 2019, 7, 332. [CrossRef]

38. Bayona-Serrano, J.D.; Viala, V.L.; Rautsaw, R.M.; Schramer, T.D.; Barros-Carvalho, G.A.; Nishiyama, M.Y.; Freitas-de-Sousa, A.L.; Moura-da Silva, A.M.; Parkinson, C.L.; Grazziotin, F.G.; et al. Replacement and parallel simplification of nonhomologous proteinases maintain venom phenotypes in rear-fanged snakes. Mol. Biol. Evol. 2020, 37, 3563-3575. [CrossRef]

39. Heyborne, W.H.; Mackessy, S.P. Identification and characterization of a taxon-specific three-finger toxin from the venom of the Green Vinesnake (Oxybelis fulgidus; Family Colubridae). Biochimie 2013, 95, 1923-1932. [CrossRef]

40. Modahl, C.M.; Mrinalini.; Frietze, S.; Mackessy, S.P. Adaptive evolution of distinct prey-specific toxin genes in rear-fanged snake venom. Proc. R. Soc. B Biol. Sci. 2018, 285. [CrossRef]

41. Fry, B.G.; Scheib, H.; de Azevedo, I.d.L.J.; Silva, D.A.; Casewell, N.R. Novel transcripts in the maxillary venom glands of advanced snakes. Toxicon 2012, 59, 696-708. [CrossRef]

42. Von Reumont, B.M. Studying smaller and neglected organisms in modern evolutionary venomics implementing RNASeq (Transcriptomics) - A critical guide. Toxins 2018, 10, 292. [CrossRef]

43. Haney, R.A.; Clarke, T.H.; Gadgil, R.; Fitzpatrick, R.; Hayashi, C.Y.; Ayoub, N.A.; Garb, J.E. Effects of gene duplication, positive selection, and shifts in gene expression on the evolution of the venom gland transcriptome in widow spiders. Genome Biol. Evol. 2016, 8, 228-242. [CrossRef]

44. Drukewitz, S.H.; Fuhrmann, N.; Undheim, E.A.; Blanke, A.; Giribaldi, J.; Mary, R.; Laconde, G.; Dutertre, S.; von Reumont, B.M. A dipteran's novel sucker punch: Evolution of arthropod atypical venom with a neurotoxic component in robber flies (Asilidae, Diptera). Toxins 2018, 10, 29. [CrossRef]

45. Ellsworth, S.A.; Nystrom, G.S.; Ward, M.J.; Freitas de Sousa, L.A.; Hogan, M.P.; Rokyta, D.R. Convergent recruitment of adamalysin-like metalloproteases in the venom of the Red Bark Centipede (Scolopocryptops sexspinosus). Toxicon 2019, 168, 1-15. [CrossRef]

46. Modahl, C.M.; Brahma, R.K.; Koh, C.Y.; Shioi, N.; Kini, R.M. Omics technologies for profiling toxin diversity and evolution in snake venom: Impacts on the discovery of therapeutic and diagnostic agents. Annu. Rev. Anim. Biosci. 2020, 8, 91-116. [CrossRef] 
47. Calvete, J.J.; Bonilla, F.; Granados-Martínez, S.; Sanz, L.; Lomonte, B.; Sasa, M. Venomics of the Duvernoy's gland secretion of the False Coral Snake Rhinobothryum bovallii (Andersson, 1916) and assessment of venom lethality towards synapsid and diapsid animal models. J. Proteom. 2020, 225. [CrossRef]

48. Uetz, P.; Freed, P.; Hošek, J. The Reptile Database. Available online: http://www.reptile-database.org/ (accessed on 1 May 2020).

49. Anderson, P. The Reptiles of Missouri; University of Missouri Press: Colombia, MO, USA, 1965; pp. 1-319.

50. Trauth, S. Posterior maxillary fangs of the Flathead Snake, Tantilla gracilis (Serpentes: Colubridae), using scanning electron microscopy. J. Ark. Acad. Sci. 1991, 45, 133-136.

51. Greene, H. Snakes: The Evolution of Mystery in Nature; University of California Press: Berkeley, CA, USA, 1997.

52. Hill, R.E.; Mackessy, S.P. Venom yields from several species of colubrid snakes and differential effects of ketamine. Toxicon 1997, 35, 671-678. [CrossRef]

53. Hill, R.E.; Mackessy, S.P. Characterization of venom (Duvernoy's secretion) from twelve species of colubrid snakes and partial sequence of four venom proteins. Toxicon 2000, 38, 1663-1687. [CrossRef]

54. Wilson, L.D.; Mata-Silva, V. A checklist and key to the snakes of the Tantilla clade (Squamata: Colubridae), with comments on taxonomy, distribution, and conservation. Mesoamerican Herpetol. 2015, 2, 418-498.

55. Antúnez-Fonseca, C.A.; Castro, J.A.; España, F.G.; Townsend, J.H.; Wilson, L.D. A new species of Tantilla of the taeniata group (Squamata: Colubridae) from Refugio de Vida Silvestre Barras de Cuero y Salado in Caribbean coastal Honduras. Amphib. Reptile Conserv. 2020, 14, 86-102.

56. Ernst, C.; Ernst, E. Snakes of the United States and Canada; Smithsonian Books: Washington, DC, USA, 2003.

57. Holm, P. Phylogenetic Biology of the Burrowing Snake Tribe Sonorini (Colubridae). Ph.D. Thesis, University of Arizona, Tucson, AZ, USA, 2008.

58. Todd, B.D.; Willson, J.D.; Winne, C.T.; Semlitsch, R.D.; Gibbons, J.W. Ecology of the Southeastern Crowned Snake, Tantilla coronata. Copeia 2008, 2, 388-394. [CrossRef]

59. Farrell, T.M.; Smiley-Walters, S.A.; McColl, D.E. Prey species influences foraging behaviors: Rattlesnake (Sistrurus miliarius) predation on Little Brown Skinks (Scincella lateralis) and Giant Centipedes (Scolopendra viridis). J. Herpetol. 2018, 52, 156-161. [CrossRef]

60. Hamanaka, K.; Mori, A. Toxicity of venom from the Mamushi, Gloydius blomhoffii, (Squamata, Crotalinae) to centipedes. Toxicon 2020, 188, 11-15. [CrossRef] [PubMed]

61. Degenhardt, W.; Painter, C.; Price, A. Amphibians and Reptiles of New Mexico; University of New Mexico Press: Albuquerque, NM, USA, 1996.

62. Parga, V. Arthropod Diets in Chihuahuan Desert Snakes. Master's Thesis, University of Texas, El Paso, TX, USA, 2018.

63. Saviola, A.J.; Peichoto, M.E.; Mackessy, S.P. Rear-fanged snake venoms: An untapped source of novel compounds and potential drug leads. Toxin Rev. 2014, 33, 185-201. [CrossRef]

64. Boyer, D.M.; Gunnell, G.F.; Kaufman, S.; McGeary, T.M. MorphoSource: Archiving and sharing 3-D digital specimen data. Paleontol. Soc. Pap. 2016, 22, 157-181. [CrossRef]

65. Hargreaves, A.D.; Swain, M.T.; Hegarty, M.J.; Logan, D.W.; Mulley, J.F. Restriction and recruitment-gene duplication and the origin and evolution of snake venom toxins. Genome Biol. Evol. 2014, 6, 2088-2095. [CrossRef]

66. Love, M.I.; Huber, W.; Anders, S. Moderated estimation of fold change and dispersion for RNA-seq data with DESeq2. Genome Biol. 2014, 15. [CrossRef]

67. Robinson, M.D.; McCarthy, D.J.; Smyth, G.K. edgeR: A Bioconductor package for differential expression analysis of digital gene expression data. Bioinformatics 2009, 26, 139-140. [CrossRef]

68. Mcgivern, J.J.; Wray, K.P.; Margres, M.J.; Couch, M.E.; Mackessy, S.P.; Rokyta, D.R. RNA-seq and high-definition mass spectrometry reveal the complex and divergent venoms of two rear-fanged colubrid snakes. BMC Genom. 2014, 15, 1061. [CrossRef]

69. Modahl, C.M.; Frietze, S.; Mackessy, S.P. Transcriptome-facilitated proteomic characterization of rear-fanged snake venoms reveal abundant metalloproteinases with enhanced activity. J. Proteom. 2018, 187, 223-234. [CrossRef]

70. de Oliveira, F.A.; de França, R.C.; França, F.G.R. Geographical ecology of Tantilla melanocephala (Squamata: Serpentes: Colubridae) in a Neotropical region: A comparison of northeastern Atlantic Forest and Caatinga populations. Stud. Neotrop. Fauna Environ. 2020, 1-10. [CrossRef]

71. Cobb, V.A. Diet and prey size of the Flathead Snake, Tantilla gracilis. Copeia 2004, 2, 397-402. [CrossRef]

72. Conroy, C.; Papenfuss, T.; Parker, J.; Hahn, N. Use of Tricaine Methanesulfonate (MS222) for euthanasia of reptiles. J. Am. Assoc. Lab. Anim. Sci. 2009, 48, 28-32.

73. Rokyta, D.R.; Lemmon, A.R.; Margres, M.J.; Aronow, K. The venom-gland transcriptome of the Eastern Diamondback Rattlesnake (Crotalus adamanteus). BMC Genom. 2012, 16, 312. [CrossRef]

74. Rokyta, D.R.; Wray, K.P.; McGivern, J.J.; Margres, M.J. The transcriptomic and proteomic basis for the evolution of a novel venom phenotype within the Timber Rattlesnake (Crotalus horridus). Toxicon 2015, 98, 34-48. [CrossRef]

75. Rokyta, D.R.; Margres, M.J.; Ward, M.J.; Sanchez, E.E. The genetics of venom ontogeny in the Eastern Diamondback Rattlesnake (Crotalus adamanteus). PeerJ 2017, 5, e3249. [CrossRef]

76. Zhang, J.; Kobert, K.; Flouri, T.; Stamatakis, A. PEAR: A fast and accurate Illumina Paired-End reAd mergeR. Bioinformatics 2014, 30, 614-620. [CrossRef] 
77. Holding, M.L.; Margres, M.J.; Mason, A.J.; Parkinson, C.L.; Rokyta, D.R. Evaluating the performance of de novo assembly methods for venom-gland transcriptomics. Toxins 2018, 10, 249. [CrossRef]

78. Haas, B.J.; Papanicolaou, A.; Yassour, M.; Grabherr, M.; Blood, P.D.; Bowden, J.; Couger, M.B.; Eccles, D.; Li, B.; Lieber, M.; et al. De novo transcript sequence reconstruction from RNA-seq using the Trinity platform for reference generation and analysis. Nat. Protoc. 2013, 8, 1494-1512. [CrossRef]

79. Fu, L.; Niu, B.; Zhu, Z.; Wu, S.; Li, W. CD-HIT: Accelerated for clustering the next-generation sequencing data. Bioinformatics 2012, 28, 3150-3152. [CrossRef]

80. Li, H. Aligning sequence reads, clone sequences and assembly contigs with BWA-MEM. arXiv 2013, arXiv:1303.3997.

81. Stothard, P. The sequence manipulation suite: JavaScript programs for analyzing and formatting protein and DNA sequences. BioTechniques 2000, 28. [CrossRef]

82. Li, B.; Dewey, C.N. RSEM: Accurate transcript quantification from RNA-Seq data with or without a reference genome. BMC Bioinform. 2011, 12. [CrossRef]

83. Langmead, B.; Salzberg, S.L. Fast gapped-read alignment with Bowtie 2. Nat. Methods 2012, 9, 357-359. [CrossRef]

84. Palarea-Albaladejo, J.; Martín-Fernández, J.A. ZCompositions-R package for multivariate imputation of left-censored data under a compositional approach. Chemom. Intell. Lab. Syst. 2015, 143, 85-96. [CrossRef] 